\title{
A VIEW ON RIVER CHANNEL PROCESS AND SEDIMENT TRANSPORT, AS ONE OF CONVENTIONAL YET CURRENT SUBJECTS IN HYDRAULIC ENGINEERING
}

\author{
Yuichiro FUJITA ${ }^{1}$

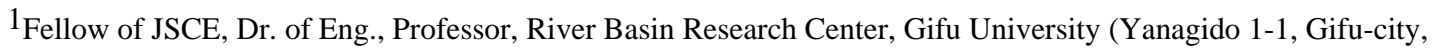 \\ Gifu 501-1193, Japan)
}

\begin{abstract}
The river channel process is one of conventional yet current subjects in hydraulic engineering, and sediment transport phenomena play important roles in the process. Studies on the process have been carried out from two standpoints, practical necessity of river training and intellectual curiosity or scientific interest in fluvial morphology, though the sediment transport had been investigated mainly from practical requests. As studies on river channel process have rather long history and wide variety of background, so background and development of the research in Japan are described briefly and some comments are given on current researches and near future studies.
\end{abstract}

Key Words : River channel process, sediment transport, sand bar formation, overview

\section{INTRODUCTION}

Probably, Senior researchers in their about sixties or more may feel a kind of generation gap to see recent state of studies on river channel processes, comparing them to those at their young ages. As said that "Rivers are living things", its changes seemed to be unrestricted and unpredictable then, but 2-D changes with 3-D flow fields are predicted by some numerical analysis of river bed variations by the use of basic equations with newly findings in the subsequent researches. Thus, river channel process is one of conventional yet current subjects in hydraulic engineering, and sediment transport phenomena play important roles in the process. The former have been studied from two standpoints, practical necessity in river engineering and intellectual curiosity or scientific interest in fluvial morphology, though the latter sediment transport had been investigated mainly from practical requests with mechanical approach. As studies on river channel process have rather long history and wide variety of background, so it needs to organize the discussion points in order to review them even from personal experience. Here, background and development of the research in Japan are described briefly according to the author's experience and some comments are given on current researches.

\section{AN OVERVIEW OF BACKGROUND AND STUDIES ON RIVER CHANNEL PROCESS IN JAPAN}

Studies on river channel process occupy main portions of those on fluvial processes carried out in geographical, geomorphological and geophysical fields with scientific interests such as those in cause of river meandering while in civil engineering on flood defense and river training for land protection and navigation.

In Japan after World War II, the researches were started from practical field, because devastate country caused severe flood disaster and battered Japanese economy sought reasonable way with light financial burden against it, and investigations on stable channel and related topics were commenced. In general, clarification of natural phenomena starts from both field observations and fundamental 
experiments. Thus, measurement on sediment load were conducted by Public Works Research Institute, the Ministry of Construction at the time, devising field sediment samplers, while several experiments were carried out on meandering and bar formation in some places. However, high economic growth enabled countermeasure against flood with heavy usage of concrete and weakened practical demand to the studies on the stable channel. This change in investigation environment produced a kind of the dissociation of the practice and the field researches

Another background of this situation was the state of the arts in the research then, scare technologies in practical use. Only a few were applied tentatively to obtain not quantitative but qualitative information, such as critical shear stress, one-dimensional analysis of riverbed variations with uniform sand. Suitability and applicability of sediment load formulae did not been verified sufficiently. Moreover, rather than that the process had not been clarified, it seemed that it had been obscure what was the problem to be clarified first in the complicated process.

Consequently, fundamental experiments on river channel process were carried out everywhere to grasp the phenomena in the process, for example, self-formed channel or stable channel on alluvium, as well as theoretical studies on sediment transport, which is one of essential element in the process. Some works,1),2) on river channel migrations and sand bar formation is the pioneer in this context. Since sand bar formation and bank erosion are dominant phenomena in the process, they were investigated by fundamental experiments and by theoretical considerations. Many empirical and substantial information accumulated from the experiments have promoted the development of theoretical and numerical works, such as linear and weak nonlinear analyses on bar formation and interaction between them and channel meandering. Recent works by Izumi ${ }^{3)}$, Pornprommin et al. ${ }^{4)}$ and Watanabe ${ }^{5)}$ advance the theoretical approach on bar phenomena while those by Nagata, Hosoda et al. ${ }^{6}$, Kuimura et al. $^{7)}$ and Shimizu ${ }^{8)}$ develop numerical method to river channel process, introducing turbulence models in the scheme.

\section{ESSENTIAL VIEWPOINT ON THE RIVER CHANNEL PROCESS AND REMAINING PROBLEMS}

First, since river channels exist in every place in river basins and sediment as well as water moves downstream from headwaters in mountainous regions to river mouths at shores usually.
Therefore, the river channel process must be studied on a location with definite boundary conditions, especially upstream input conditions.

The inherent property of the substance must be recognized fundamentally and it is natural to treat water as continuum and to regard sediment as granular material. Taking this into consideration, attention should be paid to that convenient and pragmatic ways to solution, like as MPS method ${ }^{9}$, are employed because the most efficient measure is digital computer. Approach to mass movement by Shimizu et al. ${ }^{10)}$ and that to suspended sediment by Sekine ${ }^{11)}$ seem very natural in this meaning.

Though pursuit of originality and new theme is inevitable as the destiny of the investigation, only introduction of new technique should be avoided. In case of experiment, hydraulic conditions and/or material properties must be extended from the previous ones, such as data extent of reference concentration of suspended sediment. The experiment also must be carried out with clear intention. Otherwise, it may be criticized as an adult playing with sand and water.

It is recommended to collect verification data of actual scale of sediment transport by utilizing large reservoir sedimentation data as Sakuma dam ${ }^{12)}$ to raise the accuracy of riverbed variation because bed change data only indicate differences of sediment load between neighboring cross sections.

\section{REFERENCES}

1) Kinoshita, R.: Study on the channel evolution of the Ishikari river, Resources, Science and Technology Agency, Research Report , No.36, 1962 (in Japanese).

2) Fujita, Y. and Muramoto, Y.: Bulletin, DPRI, Kyoto Univ., Vol.32, Part 1, 1982.

3) IZUMI, N.: J.: JSCE, No. 712 / II -60, 45-56, 2002

4) Pornprommin, P.A., Izumi, N. and Tsujimoto, T.: Annual J. Hydraulic Eng., JSCE, Vol.48, pp1009-1014, 2004.

5) Watanabe, Y.: Annual J. Hydraulic Eng., JSCE, Vol.50, 967-972, 2006.

6) Nagata, N., Hosoda, T., Muramoto, Y. and Nakato, T.: J., JSCE, No. 684 / II -56, 2001, pp. 21-34

7) Kimura, I., Hosoda, T. and ONDA, S.: Annual J. Hydraulic Eng., JSCE, Vol.49, 559-564, 2005.

8) Shimizu, Y.: Annual J. Hydraulic Eng., JSCE, Vol.47, 643-648, 2003.

9) Goto, H, Sumi, T. and Sakai, T.: J. JSCE, B, Vol. 62, No. 2, 201-209, 2006.

10) Shimizu, Y. and Osada, K.: Annual J. Hydraulic Eng., JSCE, Vol.48, 901-906, 2004.

11) Sekine, M.: J. JSCE, B, Vol. 63, No. 4, 311-322, 2007.

12) Shinjo, T., Fujita, Y. and Ohhashi, K. Annual J. Hydraulic Eng., JSCE, Vol.51, 937-942, 2007.

(Received January 31, 2008) 